\title{
A Virtual Training Environment: A Framework and an Effectiveness Measurement Method
}

\author{
Fahad M Alotaibi ${ }^{1}$, Manal N Alasmari ${ }^{2}$ \\ Associate Professor, Computer Information Systems, Faculty of Computing and Information Technology, \\ King Abdul-Aziz University, Jeddah, Saudi Arabia ${ }^{1}$ \\ Master Student, Computer Information Systems, Faculty of Computing and Information Technology, \\ King Abdul-Aziz University, Jeddah, Saudi Arabia ${ }^{2}$
}

\begin{abstract}
The virtual training enables training elements i.e. trainers and trainees to obtain the needed skills and experience through simulation of a real training process. Nowadays, there is extreme need for distance education and training due to the spread of the Covid 19 epidemic. For this reason, we proposed framework for virtual training system and made a simple evaluation to prove its efficiency and effectiveness. we conducted an interview with one lecturer and made questionnaire for 11 computer science master students. These ways can measure the return of the training and therefore enhance its quality and address some issues that the traditional training face.
\end{abstract}

Keywords: Virtual Classes, Second Life, E-training, Return of Training, E-learning, Smart Systems.

\section{INTRODUCTION}

The tremendous development of information and communication technologies has resulted in the emergence of modern electronic educational resources which scientific studies and research have proven their effectiveness in education and training; such as: Virtual Classroom and Mobile Learning (Khatwah, 2013).

Thus, we should develop the training members skills in using these resources to enhance the effectiveness and efficiency of the training process. Virtual training process relays on social interactions between trainers and trainees in a virtual platform. Its most distinctive feature is that it is populated, this means it is connected to all trainers and trainees. Trainers can use the simulation environment to clarify their content to help trainees to understand the course materials (Alotaibi, 2014).

Training elements must ensure the effectiveness of virtual training process. This achieved by measuring the return of training by specific methods and tools. However, there is still lack tools to measure the virtual training effectiveness. For example, conducting interviews and questionnaires is useful to ensure users satisfaction and benefit from their opinions and ideas for future system improvements. Therefore, this paper shows this effective measurement method for the quality of virtual training and ensuring its usefulness for trainers and trainees alike.

\section{LITERATURE REVIEW}

In this section, we will review the main concepts of this research scope.

\section{- $\quad$ Virtual Reality (VR)}

It is a simulation environment in which the computer presents the real person in an imaginary world. It is an interactive and attractive experience which allows the users interact with the virtual environment through input devices like keyboards and microphones or by special equipment such as wired gloves.

In VR, users feel like they can touch the 3D virtual objects in the simulated environment. This allows them to imagine that these objects are already exist and therefore help to understand and analyse (Halarnkar, 2012).

- $\quad$ E-learning

Many researchers claim that the e-learning is a wide concept. it defined by the performance of the learners, the extent of the use and benefit from the existing learning techniques, exploit the learning chances, improve the learning process, support for learners to achieve learning goals (Zhongke, 2012). 


\section{International Advanced Research Journal in Science, Engineering and Technology}

Vol. 7, Issue 8, August 2020

\section{DOI 10.17148/IARJSET.2020.7819}

\section{- $\quad$ Smart Systems}

Smart systems define as systems consist of special devices and parts built-in or linked to the system to act in a systematic way. they programmed in a specified manner to simulate a biological task (Akhras, 2000).

\section{SECOND LIFE (SL)}

In our experience we chose SL as virtual environment to conduct the virtual training. In this section we will review SL and its components.

\section{A. Overview}

Second Life is essentially a game. It can be considered as a video game where you can make a 3D objects called avatars. Theses avatars interact with each other within the virtual world.

They can walk, talk and do anything in this world. Second life enables people to reincarnate and become the people they want to be in real life. It is one of the best techniques for training and teaching by using virtual environment, where we can create training hall with its necessary equipment and services. We only need computer and internet connection to create such virtual hall.

Second Life is a virtual environment tool, multiple users can reach it simultaneously for both official and unofficial learning. It made a new revolution in social learning concept which claims that people learn effectively by engaging with their social context (Alotaibi, 2014).

B. Components of SL

There are three components of SL:

1. Technical infrastructure: Creating virtual environment in second life needs tools and processes that don't differ too much than electronic objects used in computerized application development. Simple building blocks like cubes and cylinders are joined as composite 3D objects. Embedded scripts are used to make an interaction between objects.

2. Immersion and co-presence: Yee, Bailenson, Urbanek, Chang and Merget (2007) have investigated the social standards and performances of avatars within SL. They found that avatars performed very much similar to real-world persons. In an educational context, coexistence can be connected to the idea of learner and instructor existence, fundamental elements in Garrison and Anderson's (2003) community of inquiry model (COI). In the COI model, the capabilities of both learner and instructor to involve themselves into the educational environment are basic elements to successful learning dealings. These results propose that the immersive character of the virtual world can present a persuasive learning experience, particularly in relation to simulation and role-playing activities.

3. Socialisation and social objects: Social activities and socialisation lead the utilization of SL and are assisted by various communication channels, observable avatar profiles and the built architecture and objects. In-world socialization is observable in the links that form within virtual communities. Engeström's (2005) perception of objects and people can explain why virtual environments such as SL are so successful. It is the strong and direct relationship between people and virtual objects, and the importance of shared interest through social objects, that create the conditions under which these social spaces work (Warburton, 2009).

\section{A DESCRIPTIVE FRAMEWORK FOR VIRTUAL TRAINING HALL IN SL}

We developed a descriptive framework to explain the way in which the training members acquire the necessary skills and experience in a virtual training hall. This framework proved that the training members obtained an extreme benefit from the experience in SL. It connects the basic components of training process in SL and shows how they can interact with each other as shown in Fig 1. 


\section{DOI 10.17148/IARJSET.2020.7819}

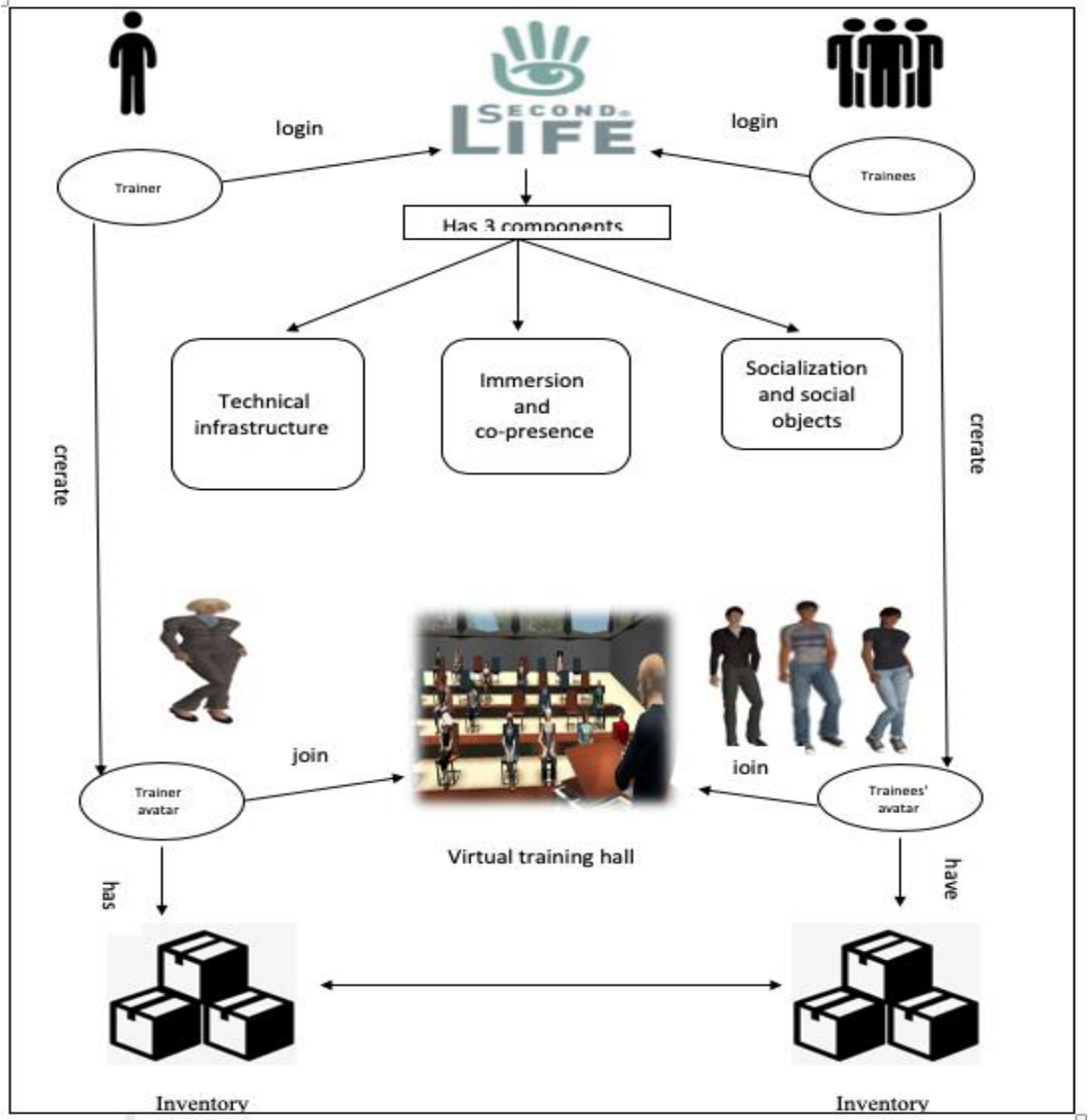

Fig. 1 Framework for virtual training hall in SL

\section{EVALUATION METHODS}

A. KIRKPATRIC'S MODEL: Kirkpatrick (1998) was interested in the field of training and suggested four areas that require measurement to determine the efficiency and effectiveness of training programs. The areas are emotional reaction, achievement of objectives, behavioral changes and organizational impact as shown in Fig 2. In the following we will discuss the four areas in details.

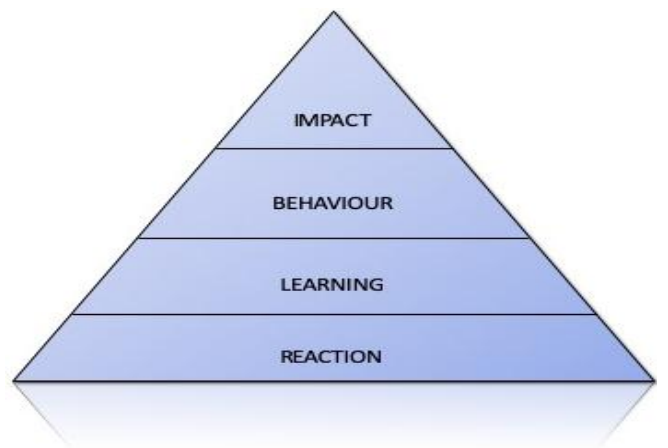

Fig. 2 Kirkpatric model

1. Emotional Reaction: Emotional reaction means the trainees' behavior and how their skills and experience changed and improved after the training. In general, emotional reaction be consider a standard for evaluating trainee's attitude, expectations, and goals. Therefore, observers can obtain feedback on training course. This standard measured by questionnaire or interviews with trainers, trainees, and observers. 


\section{International Advanced Research Journal in Science, Engineering and Technology}

Vol. 7, Issue 8, August 2020

\section{DOI 10.17148/IARJSET.2020.7819}

2. Achieving Learning Objectives: In this standard, the responsible can make post training evaluation to measure the achieved objectives and therefore improve job performance. A positive feedback and functional skill development are pointers of the training success. Pre and post-test methods can be used to evaluate the training effectiveness. The result of these tests will compared to a benchmark which used to insure that the required expertise and information have been gained from the training experience. Finally, the result should be compared to the learning objectives.

3. Behavioral Changes: This standard measure the changes on trainees' behavior that affect their job performance after the training. Measuring behavioral changes cannot be made immediately after training. It requires some time for trainees to apply the skill and knowledge that obtained from training experience. These changes can be measured by many ways like surveys, observations and interviews of performance. A common technique to measure behaviors is by setting initial performance objectives. Achieving these objectives is an indicator of the usefulness of the emotional reaction and learned skills and transferring them into behavioral changes.

4. Impact on Organization: This measurement focuses on the idea that the training programs should be corresponding to the culture and strategy of the organization. The success of the training program depends on the organization's goals achievement.

\section{DESCRIPTIVE STATISTICS}

\section{A. Quantitative method}

Questionnaire concerning a virtual training environment: a framework and an effectiveness measurement method. It contains 7 questions. We distributed the questionnaire to computer science master students and we got 11 responses as follows:

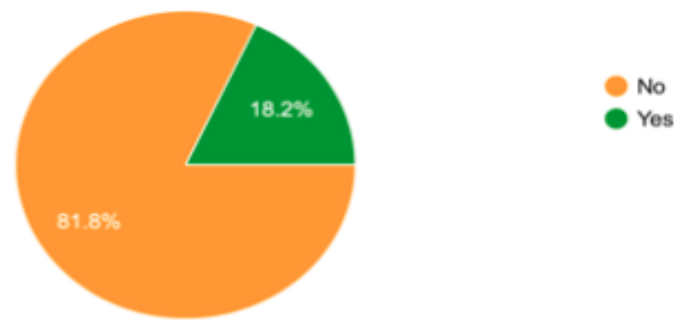

Fig. 3 Students' background about virtual training $2 \backslash$ If you have already been trained in a virtual environment, write it here: 1 response

Zoom meeting: The first question was "have you ever trained in virtual environment?". All participants said no except one of them. She trained in "zoom meeting" which provides remote conferencing services using cloud computing. Zoom offers communications software that combines video conferencing, online meetings, chat, and mobile collaboration (Anon., n.d.). zoom meeting similar to blackboard system i.e. it is not fully virtual like second life and other virtual environments.
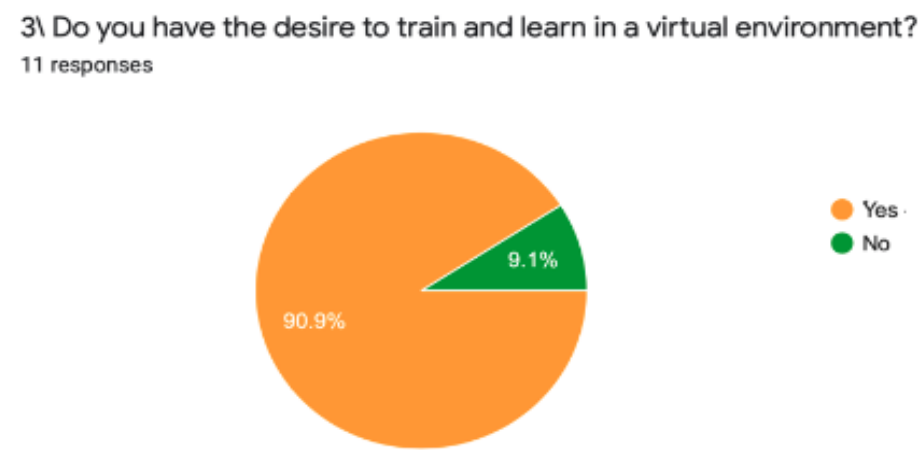

Fig. 4 Type of training the students prefer

The third question was " Do you have the desire to train and learn in virtual environments?" All participants want to learn and practice in virtual environments except one that may have ambiguity in the concept of virtual environments and ways to deal with them. 
International Advanced Research Journal in Science, Engineering and Technology

Vol. 7, Issue 8, August 2020

DOI 10.17148/IARJSET.2020.7819

4/ When you are offered an electronic training program do you prefer to use: 11 responses

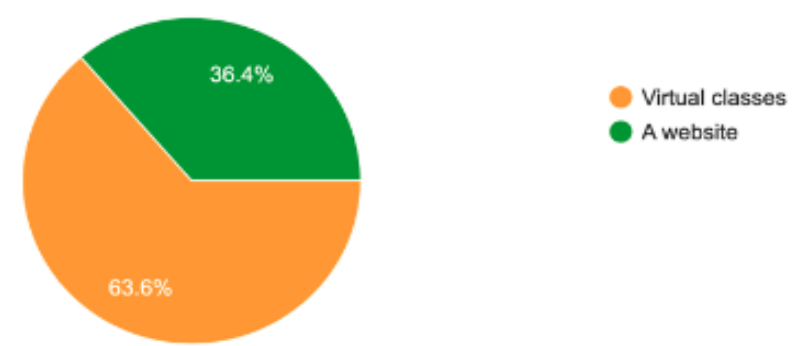

Fig. 5 Type of training the students choose

In question 4 we asked participants about their preference: virtual environment or website for training? And the result was $63.6 \%$ prefer virtual environment.

51 What is the most efficient, flexible and interesting method for training, from your point of view: 11 responses

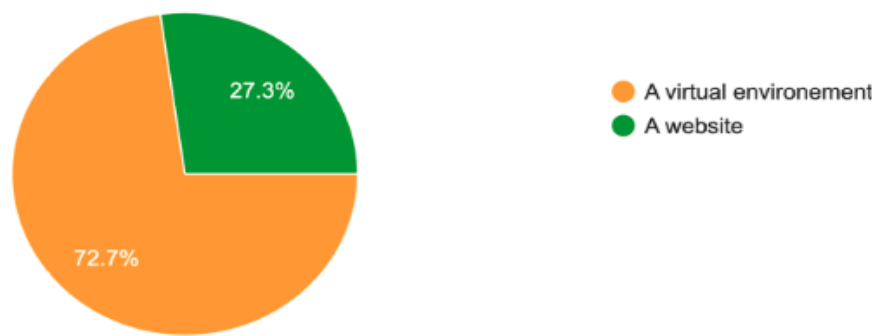

Fig. 6 Virtual training and websites

From question 5 we extracted that the virtual environments are more efficient, flexible and interesting than websites.

6/ Do you think that there is difficulty in measuring the return from e-training?

11 responses

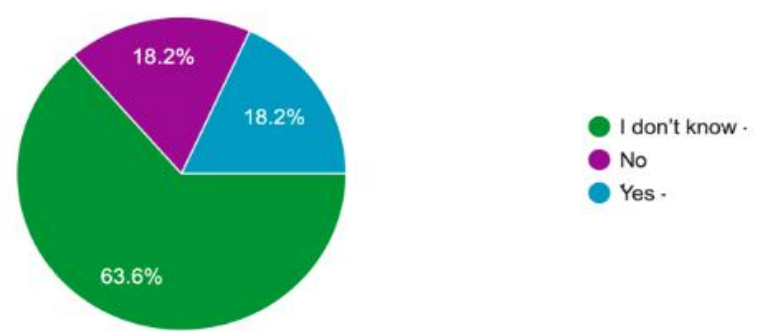

Fig. 7 Difficulty in measuring the return of e-training

7/ What is the most appropriate way to measure the effectiveness and efficiency of courses offered electronically?

11 responses

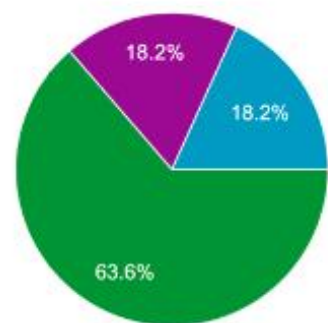

Conducting pre and post tests for trainees

Conducting interviews with trainees

Making questionnaires and surveys

Fig. 8 Suggested ways to measure the effectivity and efficiency of virtual training 


\section{International Advanced Research Journal in Science, Engineering and Technology}

Vol. 7, Issue 8, August 2020

\section{DOI 10.17148/IARJSET.2020.7819}

The results of questions 6 and 7 shows that there is difficulty and ambiguity in the process of measuring the efficiency and effectivity of virtual training. This is our mission and what our research seek to do.

\section{B. Qualitative Method}

We conducted interview with Fatimah Mahdli, a lecturer in Umm AlQura University, computer science college and has good experience in virtual training. We asked her: what is your opinion about the training in virtual environments? Her reply was: " Training tools are essential to allow distance learning. many of them considered as the state-of-the art tools and others are considered traditional tools now. I dealt with both techniques recently.

Virtual training is one of the powerful emerging technology which I think is a great contributor to the learning and training process. I used different virtual training tools to achieve different goals.

Blackboard is one of the famous virtual training I used blackboard two times once as student and another time as an instructor. It provides a lot of features. as student it allowed me to access content, track updates, and upload files and track grades. It allowed me to keep progress in the course by being engaged in the process. As instructor, blackboard allowed me to organize my material, make it available to students and make an online assessment exam for them and provide my notes upon their performance.

I think virtual training system has the advantage of engaging the trainee in the process of training, tracking the progress of trines and provide various assessment choices. It also, provide a personal learning experience for both trainer and trainees.

From the traditional training tools, I used Udacity to take a python course, the website allowed me to register an account in the website and then buy the course and have it available in my account to watch lesson by lesson. I completed the course and learned about Python, but I think this traditional way of learning has some drawbacks. It does not allow for anything rather than watching the videos that contain the course. The assessment way is very simple, just few multiplechoice questions. There is no grading system or any tool to track progress in the course. Also, it has wide timing style there is no commitment to attend the course at certain times, which might lead the trainee to quit attending the course or take long period before finishing the course".

\section{CONCLUSION}

We conclude by saying that the use of technology as a tool in learning and training becomes imperative especially in the current time where the world striving to impose social distancing to limit the spread of Corona virus. In this paper, we talked about training in virtual environments which is an effective medium that has a positive impact in achieving educational goals. Some advantages of virtual training is that it engages the trainees in the training process. Also, the use of these environments' features such as graphic animations, audio and video attracts trainees and make them interesting. Finally, the trainees' interaction skills, communication, and computer skills greatly improve by the using of the virtual environments. However, managing virtual training systems and measuring the effectiveness of their quality still challenging. There is a lack of studies and researches that discuss the tools and methods used to analyse trainers and trainees behavior. The feasibility also of training through virtual environments is still unclear and not specific

\section{REFERENCES}

[1] Khatwah, S. A. A., 2013. Design an Innovative Virtual Training Environment and Measure Their Effectiveness in the Development of eLearning Skills Training and the Trend towards Default with Faculty Members. In: e-Learning" Best Practices in Management, Design and Development of e-Courses: Standards of Excellence and Creativity", 2013 Fourth International Conference on. s.1.:IEEE, pp. 260--260.

[2] Alotaibi, F. M., 2014. Classroom Simulation for Trainee Teachers Using 3D Virtual Environments and Simulated Smartbot Student Behaviours, s.l.: s.n.

[3] Halarnkar, P. a. S. S. a. S. H. a. S. H. a. S. A., 2012. A review on virtual reality. IJCSI International Journal of Computer Science, p. 6.

[4] Ulewicz, S. a. P. D. a. V.-H. B., 2016. Interdisciplinary Communication and Comprehension in Factory Automation Engineering-A Concept for an Immersive Virtual Environment. IFAC-PapersOnLine, Volume 49, pp. 227--232.

[5] Akhras, G., 2000. Smart materials and smart systems for the future. Canadian Military Journal, Volume 1, pp. 25--31.

[6] Warburton, S., 2009. Second Life in higher education: Assessing the potential for and the barriers to deploying virtual worlds in learning and teaching. British journal of educational technology, pp. 414-426.

[7] Anon., n.d. wikipedia. [Online]

Available at: https://en.wikipedia.org/wiki/Zoom_Video_Communications [Accessed 412 2019].

[8] AlYahya, M. S. a. B. M. N., 2013. Evaluation of effectiveness of training and development: The Kirkpatrick model. Asian Journal of Business and Management Sciences, pp. 14-24.

[9] Rudenko, D. a. A. B., 2007. An overview of blackboard architecture application for real tasks. s.1., Scientific Proceedings Of Riga Technical University, pp. 50-57.

[10] Zhongke, Z., 2012. Research on Enterprise E-Learning Training Application Questions and Improvement Tactics. In: Advances in Technology and Management. s.1.:Springer, pp. 71--77. 